\title{
Ranitidine and sucralfate as maintenance therapy for gastric ulcer disease: endoscopic control and assessment of scarring
}

\author{
T TAKEMOTO, M NAMIKI, M ISHIKAWA, K TSUNEOKA, S OSHIBA, \\ K KAWAI, AND N OGAWA
}

From the Yamaguchi University School of Medicine, Asahikawa Medical College, Yamagata University School of Medicine, Nippon Medical School, Osaka Medical College, Kyoto Prefectural University of Medicine, Ehime University School of Medicine, Japan

summary The efficacy of ranitidine $(150 \mathrm{mg}$ nocte), and sulcralfate (1 $\mathrm{g}$ tds) as maintenance therapy to prevent gastric ulcer relapse was evaluated in a 12 month trial in 363 patients. The relapse rates were $8 \cdot 8 \%$ at three months, $14 \cdot 7 \%$ at six months, $18 \cdot 1 \%$ at nine months, and $21 \cdot 0 \%$ at 12 months for the ranitidine group and $14 \cdot 7 \%, 21 \cdot 3 \%, 29 \cdot 9 \%$, and $30 \cdot 2 \%$ respectively for the sucralfate group. At nine and 12 months the cumulative relapse rates for the ranitidine group were significantly lower than those for the sucralfate group $(\mathbf{p}<\mathbf{0 . 0 5})$. In both groups ulcers recurred mainly from red scars observed at the endoscopic scarring stage. This indicated the necessity of drug treatment up to the white scar stage. The results suggest that ranitidine is effective in preventing gastric ulcer relapse.

Gastric acid is generally considered to be a key factor in peptic ulcer development and the histamine $\mathrm{H}_{2}$ receptor blockers which inhibit its formation have become standard therapy for treatment of both duodenal and gastric ulcer.

On average duodenal ulcer patients secrete more gastric acid than healthy control subjects. Many clinical trials have therefore been conducted with $\mathrm{H}_{2}$ blockers to evaluate their use as to prevent duodenal ulcer relapse. ${ }^{1-1}$

In contrast gastric ulcer patients as a group secrete less acid than normal and are usually considered to have an imbalance between agressive and defensive factors resulting from impaired gastric defence.

This imbalance may, in theory, be rectified by therapeutic intervention which acts to increase mucosal defence or to inhibit gastric acid and pepsin. As there is no definitive information on the relative merits of these two approaches to treatment we have conducted a large clinical trial to compare the effects of ranitidine, an agent which inhibits gastric acid secretion and sucralfate, a mucosal protective agent in the prevention of gastric ulcer relapse.

Address for correspondence: Professor T Takemoto. First Department of Medicine. Yamaguchi University School of Medicine. $11+4$ (Ogushi. Uhe-shi Yamaguchi-ken, Japan.

Accepted for publication 5 April 1989
Methods

PATIENTS

Patients whose gastric ulcers had healed after any active treatment were recruited if endoscopy had confirmed the ulcer and its healing and if they were suitable for outpatient management.

DOSAGE AND ADMINISTRATION

The effects of ranitidine (Glaxo, UK), $150 \mathrm{mg} /$ day at bedtime, and sucralfate (Chugai Pharmaceutical Co, Japan), $1 \mathrm{~g}$ tds, on the rate of gastric ulcer relapse were compared in a one year maintenance trial conducted by investigators in 72 centres.

Each patient received either four $250 \mathrm{mg}$ tablets of sucralfate three times a day (before breakfast and lunch and at bedtime) or four placebo tablets before breakfast and lunch and one $150 \mathrm{mg}$ ranitidine tablet with three placebo tablets at bedtime. In order to maintain blindness, all the drugs and placebo tablets were prepared in packages which were indistinguishable in their appearance.

TRIAL. DESIGN

Endoscopic examination of the stomach was performed on five occasions, - that is, when healing was confirmed and at three, six, nine, and 12 months 
Table 1 Exclusion criteria

\begin{tabular}{lll}
\hline Reason & Drug & Ranitidine Sucralfate \\
\hline Protocol violation & 1 & - \\
Scar of DU & 1 & - \\
Scar of linear ulcer & - & 2 \\
Combined use of anti-ulcer drug & 1 & - \\
Concurrent DU & 2 & - \\
$\begin{array}{l}\text { Gastric cancer } \\
\text { Pyloric tumour embolus by HCC +hepatic }\end{array}$ & - & 1 \\
cirrhosis & & 5 \\
Patients who failed to visit hospital after start & 4 & 8 \\
$\quad$ of trial & 9 & 8 \\
Total & & \\
\hline
\end{tabular}

Table 2 Background of patients

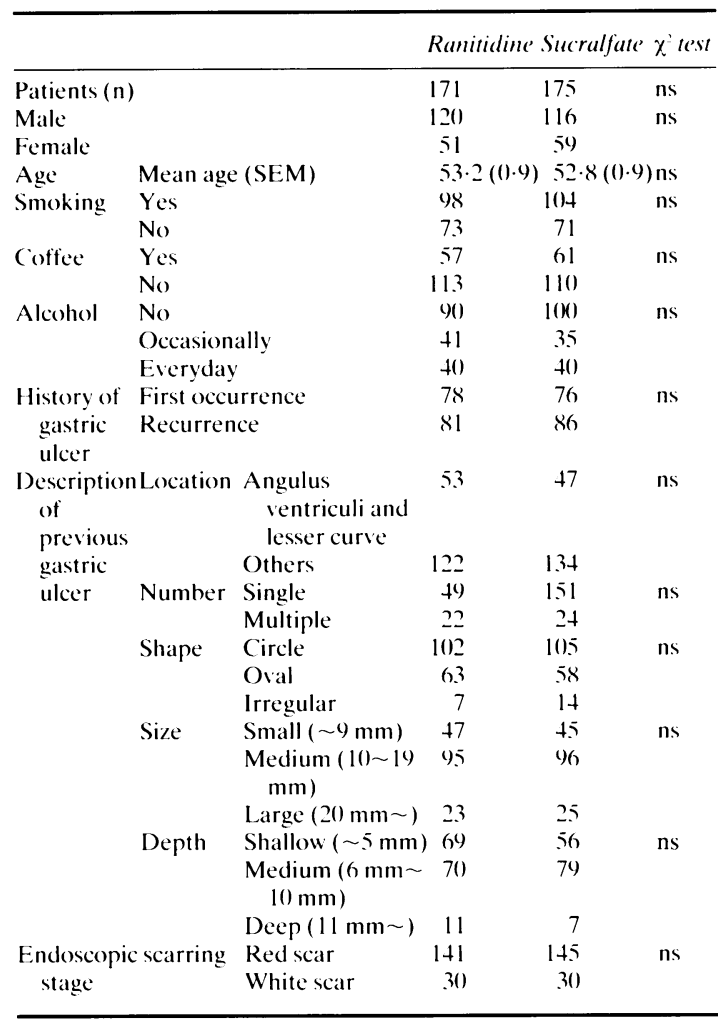

$X$ (SE). ns: No significant difference.

thereafter. Administration of the drugs was started soon after confirmation of ulcer healing by endoscopy. Furthermore, whenever recurrence was suspected from the patient's symptoms, an additional endoscopic examination was performed to confirm or deny ulcer relapse using the endoscopic scarring stages classification reported by Sakita et al.. Accord- ing to the criteria, a red scar or white scar was judged as non-relapse and the $\mathrm{A} 1, \mathrm{~A} 2, \mathrm{H} 1$, or $\mathrm{H} 2$ stages were judged as a relapse.

The patients were enrolled irrespective of their previous ulcer treatment, but patients with concurrent duodenal ulceration or those with a linear ulcer were excluded. Also excluded were patients who were or might be pregnant or lactating.

Use of all other anti-ulcer drugs was prohibited as were known ulcerogenic agents such as oral steroids and non-steroidal anti-inflammatory drugs.

To evaluate drug safety the patients were questioned concerning adverse effects. In addition clinical laboratory tests including hepatic and renal function tests and urinalysis, were performed on three occasions: at the time of confirmation of healing, and at six and 12 months after the start of maintenance therapy.

STATISTICAI. ANALYSIS

Ulcer relapse rates were calculated by Cutler-Ederer life-table analysis. The $\chi^{2}$ test by the Mantel Haenzel method was used for comparison of cumulative relapse rates. The rate of transition of the endoscopic scarring stage was also calculated by the CutlerEderer life table analysis.

The background factors of the patients were compared by the $\chi^{2}$ test.

For all of these statistical methods, $p<0.005$ was regarded as indicative of a significant difference.

\section{Results}

COMPARISON OF SUBJECTS

Three hundred and sixty three patients with a healed gastric ulcer were randomised into two groups; 180 received ranitidine and 183 patients sucralfate. Seventeen subjects were excluded for the reasons presented in Table 1. Table 2 shows the demographic data for the remaining 346 subjects (171 received ranitidine and 175 sucralfate) who were eligible for

Table 3 Previous ulcer therapy

\begin{tabular}{lcc}
\hline & \multicolumn{2}{c}{ Patients randomised to: } \\
\cline { 2 - 3 } Previous ulcertherapy & Ranitidine & Sucralfate \\
\hline $\mathrm{H}_{2}$ blocker alone ( $\left.\mathrm{H}_{2} \mathrm{RA}\right)$ & 51 & 44 \\
Sucralfate alone (S) & 0 & 1 \\
H2RA+sucralfate & 9 & 5 \\
$\mathrm{H}_{2} \mathrm{RA}+\mathrm{S}+$ others* & 32 & 30 \\
$\mathrm{H}_{2} \mathrm{RA}+$ others & 56 & 70 \\
S+others & 7 & 10 \\
Others & 16 & 14 \\
Unknown & 0 & 1 \\
\hline
\end{tabular}

* Others Gefarnate, Cetraxate, etc. 
analysis, and no significant differences were noted for any of those factors. Previous ulcer treatment for the healing phase is shown in Table 3 . In both drug groups many subjects had been treated with $\mathrm{H}_{2^{-}}$ receptor blockers but there was no difference in the distribution of any of the treatments. Also, in most cases in both groups, a red scar stage was detected at the initial endoscopic examination (Table 2).

\section{CUMULATIVE RELAPSE RATES}

Table 4 shows the relapse status for the two treatment groups for each three month period of the study. The number of patients who had relapsed was 29 for ranitidine and 44 for sucralfate. In both treatment groups, ulcer relapse occurred most frequently during the first three month period: 14 cases for ranitidine and 24 cases for sucralfate. Figure 1 shows the cumulative relapse rates with both drugs calculated by Cutler-Ederer life table analysis. The cumulative relapse rates for ranitidine at three, six, nine, and 12 months were $8.8 \%, 14.7 \%, 18.1 \%$, and $21.0 \%$, while those for the sucralfate group were $14 \cdot 7 \%, 21 \cdot 3 \%, 29 \cdot 9 \%$, and $30 \cdot 2 \%$ respectively. The cumulative relapse rates at nine and 12 months in the ranitidine group were significantly lower than those in the sucralfate group $(\mathrm{p}<0.05)$. The symptomatic relapse rates at three and six months were $6.9 \%$ and $10.9 \%$ for the ranitidine group and $9.2 \%$ and $10.7 \%$ for sucralfate group. The differences between the groups were not statistically significant. The symptomatic relapse rates at nine and 12 months were $11.7 \%$ and $12.7 \%$ for ranitidine and $18.5 \%$ and $19.6 \%$ for sucralfate, however, suggesting more symptomatic relapse with sucralfate but this was not statistically significant.

\section{ENDOSCOPIC SCARRING STAGE}

Figure 2 shows the breakdown of the endoscopic scarring stages for the patients who had remained in remission during the trial and for those who had relapsed immediately before confirmation of the ulcer recurrence. Approximately $79 \%$ each of the relapse cases in each group developed from a red scar, whilst $83.5 \%$ of the non-relapse cases in the

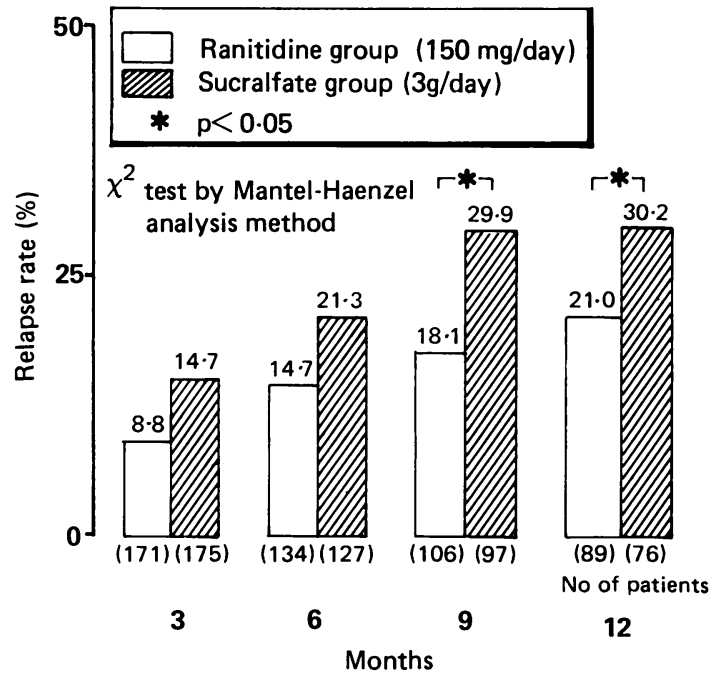

Fig. 1 Ulcer recurrence rate in each treatment group at three, six, nine, and 12 months calculated by the CutlerEderer life-table analysis method.

ranitidine groups and $71.4 \%$ of the non-relapse cases in the sucralfate group were in the white scar stage.

\section{ADVERSE EFFECTS AND LABORATORY}

ABNORMALITIES

Adverse effects developed in three of 171 patients $(1.8 \%)$ in the ranitidine group and in six of 175 patients $(3.4 \%)$ in the sucralfate group. The three patients in the ranitidine group suffered from allergic symptoms including skin rash, aggravation of chronic eczema and skin itchiness, while the six cases in the sucralfate group complained of gastrointestinal symptoms comprising gastric distension (two cases), diarrhoea, heartburn, belching, abdominal pain, and nausea.

All the adverse effects developed during the first six weeks of the trial. Those symptoms resolved or were alleviated in all cases as the drug treatment was continued or stopped.

No clinically significant changes were detected in

Table 4 Patients outcome

\begin{tabular}{|c|c|c|c|c|c|}
\hline Drug & $\begin{array}{l}\text { Patient } \\
\text { category }\end{array}$ & $\begin{array}{c}\text { Period I day-3 months } \\
\text { (I-I04 days) }\end{array}$ & $\begin{array}{l}\text { 4-6 months } \\
\text { (105-194 days) }\end{array}$ & $\begin{array}{l}7-9 \text { months } \\
\text { (195-248 days) }\end{array}$ & $\begin{array}{l}\text { 10-12 months } \\
(285-365 \text { days })\end{array}$ \\
\hline \multirow[t]{3}{*}{ Ranitidine } & Non-relapsed & 134 & 106 & 89 & 79 \\
\hline & Relapsed & 14 & $8(22)$ & $4(26)$ & $3(29)$ \\
\hline & Dropouts & 23 & $20(43)$ & $13(56)$ & $7(6.3)$ \\
\hline \multirow[t]{3}{*}{ Sucralfate } & Non-relapsed & 127 & 97 & 76 & 70 \\
\hline & Relapsed & 24 & $9(33)$ & $10(43)$ & $1(44)$ \\
\hline & Dropouts & 24 & $21(45)$ & $11(56)$ & $5(61)$ \\
\hline
\end{tabular}

( ): Number of cumulative patients. 


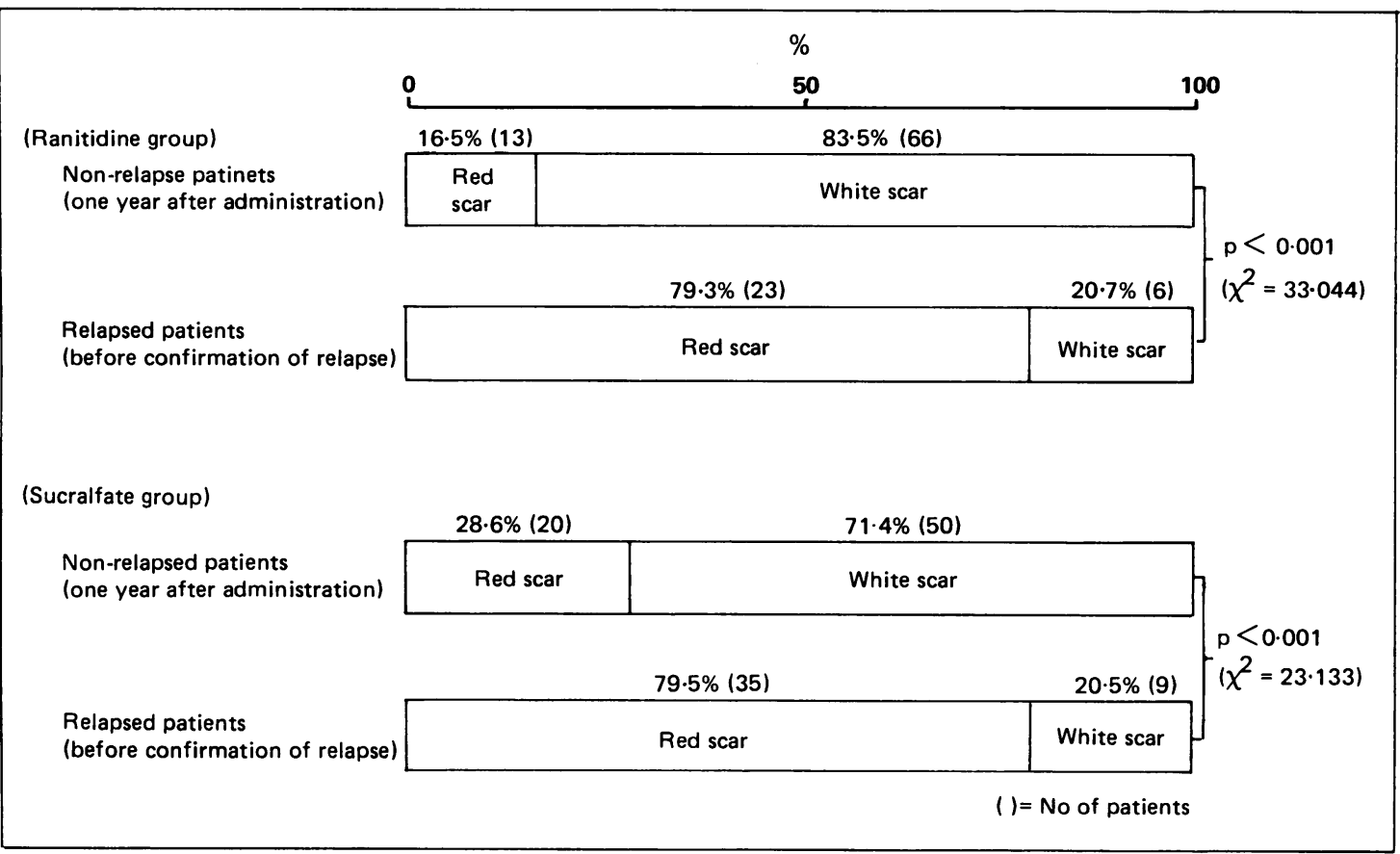

Fig. 2 Scarring stages for non-relapsed patients at the end of the study and for relapsed patients at the previous endoscopy before relapse.

routine biochemical tests (electrolytes, liver, and renal function tests) with the exception of a small increase in total serum bilirubin in one patient treated with ranitidine $(0.7 \mathrm{mg} / \mathrm{dl}$ pre-trial, $1.3 \mathrm{mg} / \mathrm{dl}$ at six months, $1.5 \mathrm{mg} / \mathrm{dl}$ at 12 months) and a slight increase in $\mathrm{LDH}$ in one patient receiving sucralfate (357 IU/l pretrial, $384 \mathrm{IU} / \mathrm{l}$ at six months, $431 \mathrm{IU} / \mathrm{l}$ at 12 months).

\section{Discussion}

A number of clinical trials have been conducted with histamine $\mathrm{H}_{2}$-receptor blockers, especially ranitidine and cimetidine to evaluate their efficacy in the prevention of peptic ulcer relapse. For both of these compounds the majority of trials have been conducted in duodenal ulcer patients. Gough et al and Silvis et $\mathrm{al}^{7}$ reported that ranitidine $150 \mathrm{mg} / \mathrm{day}$, which has a stronger inhibitory effect on nocturnal acid secretion than cimetidine $400 \mathrm{mg}$ (Santana et $a l),{ }^{x}$ showed significant superiority in terms of the cumulative relapse rate over 12 months. Reports on the prevention of gastric ulcer relapse are few. Barr $e t$ $a l^{\prime \prime}$ and Morgan et al ${ }^{\prime \prime \prime}$ reported studies with cimetidine, but the number of enrolled patients were small and their data analysis techniques were not standardised. Boyd $e^{2} a^{11}$ and Cockel et al ${ }^{12}$ studied raniti- dine's effects on ulcer relapse by recruiting a large number of patients, and they reported cumulative relapse rates for one year of $22.6 \%$ and $17 \cdot 1 \%$ respectively.

Sucralfate, the control drug for this trial, is widely prescribed in Japan for gastric ulcer treatment, and several papers ${ }^{13-15}$ have dealt with its use as maintenance therapy. In one of those reports, Marks et al ${ }^{13}$ commented that the recommended therapeutic dosage for satisfactory prevention of gastric ulcer relapse is $3 \mathrm{~g} /$ day, given as $1 \mathrm{~g}$ between breakfast and lunch and $2 \mathrm{~g}$ before bedtime.

In our study, ranitidine $150 \mathrm{mg} / \mathrm{day}$ and sucralfate $1 \mathrm{~g}$ tds (method of administration differed from that reported by Marks et al), were compared for their effects on gastric ulcer relapse. As a result, ranitidine showed a cumulative relapse rate for one year of $21.0 \%$, and its effect on ulcer relapse was significantly superior to sucralfate $(\mathrm{p}<0.05)$ after nine and 12 months treatment. In the studies by Boyd et al" and Cockel et al, ${ }^{12}$ the cumulative relapse rates for one year were also about $20 \%$. For sucralfate, Marks et al $^{14}$ reported a relapse rate of $16 \cdot 0 \%$ for six months. Our relapse rate of $21 \cdot 3 \%$ for six months was similar to their result.

In our study, endoscopic examination was conducted at three monthly intervals and at unscheduled 
times whenever the symptoms warranted; this permitted accurate monitoring of asymptomatic recurrence. The total cumulative relapse rate and the cumulative symptomatic relapse rate for the open study of Boyd et al were $22.6 \%$ and $14.0 \%$, respectively. Similar relapse rates of $21.0 \%$ and $12.7 \%$ were observed in our study, thus elucidating the ratio of symptomatic relapse to asymptomatic relapse of gastric ulcer in ranitidine maintenance therapy. In any case, in our comparative study enrolling a large number of patients, ranitidine, a histamine $\mathrm{H}_{2}$ receptor blockers, showed satisfactory prevention of gastric ulcer relapse, in which a decrease in defensive factors is said to have a strong causal relation, in comparison with sucralfate, which has a mucosal protective action. This finding suggests that ranitidine is an effective drug for gastric ulcer maintenance therapy.

The gastric ulcer relapse rate peaked during the first three months of maintenance therapy, and this may be attributable to many factors, including previous ulcer treatment. Furthermore, there is a question as to whether the relapse observed in the first three months is a genuine relapse of merely incomplete prior healing.

Peptic ulcers are judged as healed by endoscopic confirmation of a scar. Generally, in Japan scars are classified as red scars and white scars. In a study on sucralfate in the prevention of gastric ulcer relapse, Miyake et a $l^{1.3}$ reported that relapse rates are higher from red scars, suggesting that endoscopic characterisation of the scar is useful for predicting ulcer relapse.

During our study relapse in both treatment groups was greater in patients with a red scar than those having a white scar. These observations suggest that it may be necessary to continue therapy at the therapeutic dosage until confirmation of a white scar, in contrast with concluding that a red scar is proof of healing.

There is considerable discussion regarding the safety of longterm administration, including maintenance therapy, of histamine $\mathrm{H}_{2}$-receptor blockers, but because they have been clinically available for only 10 years, lifetime safety data are not available. On the other hand, sucralfate has been used for 20 years in Japan without serious side effects; it is a nonsystemic drug and therefore it is a good choice in terms of safety of longterm administration.

All the areas of adverse effects in both drug groups in this study developed during the first three months, and no severe cases were observed throughout the year. For sucralfate, no untoward effects were noted which could have been ascribed to aluminium toxicity. Further studies over a longer period and including a larger number of patients are needed to establish the safety of longterm administration of histamine $\mathrm{H}_{2}$-receptor blockers.

Based on the results of our study, administration of ranitidine, in a dose of $150 \mathrm{mg} /$ day nocte for 12 months is more effective in preventing gastric ulcer relapse than sucralfate, in a dose of $1 \mathrm{~g}$ tds (before breakfast, lunch, and bed-time).

We are grateful to Dr John $\mathrm{R}$ Wood for his critical comments on this paper.

\section{References}

1 Bardhan KD, Saul DM, Edwards JL, et al. Double-blind comparison of cimetidine and placebo in the maintenance of healing of chronic duodenal ulceration. Gut 1979; 20: $158-62$.

2 Fitzpatrick WJF, Blackwood WS. Northficld TC. Bedtime cimetidine maintenance treatment: optimum dose and effect on subsequent natural history of duodenal ulcer. (iut 1982; 23: 239-42.

3 Kozarek R, Berenson M. Berkowitz J, et al. Maintenance therapy with ranitidine following healing of acute duodenal ulcer. Curr Ther Res 1985; 38: 341-51.

4 Texter EC, Navab F, Mantell G, Berman R. Maintenance therapy of duodenal ulcer with famotidine. A multicenter United States Study. Am J Med 1986; 81 [suppl 4B]: 25-32.

5 Sakita T. Principles of gastroenterological endoscopy (in Japanese). Tokyo: Chugai-Igaku C, 197(): 32.

6 Gough KR, Korman MG, Bardhan KD, et al. Ranitidine and cimetidine in prevention of duodenal ulcer relapse. A double-blind, randomised, multicenter. comparative trial. Lancet 1984; ii: 659-62.

7 Silvis SE. Final report on the United States multicenter trial comparing ranitidine to cimetidine as maintenance therapy following healing of duodenal ulcer. J Clin Gastroenterol 1985: 7: 482-7.

8 Santana IA. Pounder RE, Orchard K. Wood EC. Chronos N. Neame R. Intragastric acidity during duodenal ulcer maintenance treatment with $\mathrm{H}_{2}$ blockers. J Clin Nutr Gastroenterol 1986; 1: 122-6.

9 Barr GD, Kang JY, Canalese J, Piper DW. A two-year prospective controlled study of maintenance cimetidine and gastric ulcer. Gastroenterology 1983; 85: 10()-4.

10 Morgan AG, Pacsoo G, McAdam WAF. Maintenance therapy: a two year comparison between Caved-S and cimetidine treatment in the prevention of symptomatic gastric ulcer recurrence. Gut 1985; 26: 599-6()2.

11 Boyd EJS, Wilson JA, Wormsley KG. Maintenance treatment of duodenal and gastric ulcer with ranitidine. Ranitidine Proceedings of an International Symposium held in the context of the seventh world congress of gastroenterology. Stockholm. 17 June 1982 , Amsterdam. 1982: 102.

12 Cockel R. Dawson J, Jain S. Ranitidine in the long-term treatment of gastric ulcers. The clinical use of ranitidine. Oxford: The Medicinc Publishing Foundation Symposium Series 5, 1982: 232. 
13 Miyake T, Ariyoshi J, Suzukaki T, Oishi M, Sakai M, Ueda S. Endoscopic evaluation of the effect of sucralfate therapy and other clinical parameters on the recurrence rate of gastric ulcers. Dig Dis Sci 1980; 25: 1-7.

14 Marks IN, Wright JP, Girdwood AH. Gilinsky NH, Lucke W. Maintenance therapy with sucralfate reduces rate of gastric ulcer recurrence. Am J Med 1985; 79 [suppl 2C]: 32-5.

15 Takemoto T, Kimura K, Okita K, et al. Efficacy of sucralfate in the prevention of peptic ulcer - double blind multicenter study with cimetidine. Scand J Gastroenterol 1987: 22 [Suppl 140]: 49-60. 